\title{
Metacognition and part-set cuing: Can interference be predicted at retrieval?
}

\author{
MATTHEW G. RHODES \\ Colorado State University, Fort Collins, Colorado \\ AND \\ Alan D. Castel \\ University of California, Los Angeles, California
}

\begin{abstract}
Although prior research has examined predictions of memory performance under conditions of interference at encoding, predictions of memory performance have not been examined for interference introduced via cues at retrieval. This was investigated in the present study by exposing participants to a random subset of to-be-recalled items just prior to retrieval (part-set cuing) and then eliciting an overall prediction of memory performance. Across three experiments, participants in part-set cuing conditions recalled proportionally fewer items than did participants who were not exposed to any cues. However, participants were unable to predict the detrimental effect of part-set cues on memory performance in either a semantic (Experiment 1) or an episodic (Experiment 2) memory task. Predictions were better calibrated after practice with part-set cuing, and there was evidence that prior experience with part-set cuing transferred to predictions made for a different part-set cuing task (Experiment 3 ). This suggests that only under some conditions are participants sensitive to the diminished accessibility of memories wrought by part-set cues and illustrates situations in which participants are or are not aware of variables at retrieval that influence memory performance.
\end{abstract}

Predictions of memory performance are of great interest to researchers for a host of applied and theoretical reasons (see Koriat, 2007; Metcalfe, 2000; and Nelson \& Narens, 1990, for reviews). The degree to which predictions are accurate assessments of future performance may not only suggest remedies for improving metacognition but also serve to increase our understanding of those cues that guide these predictions (cf. Koriat, 1997). Although individuals are often accurate in their predictions (e.g., Arbuckle \& Cuddy, 1969), a number of important discrepancies between actual and predicted performance have been documented (e.g., Carroll, Nelson, \& Kirwan, 1997; Castel, 2008; Castel, McCabe, \& Roediger, 2007; Koriat \& Bjork, 2005; Mazzoni \& Nelson, 1995; Rhodes \& Castel, in press; Zechmeister \& Shaughnessy, 1980). Many of these discrepancies represent a failure to take into account conditions that will be present during retrieval. For example, participants may misattribute ease of processing at encoding (e.g., Hertzog, Dunlosky, Robinson, \& Kidder, 2003) to anticipated ease of later retrieval (Benjamin, Bjork, \& Schwartz, 1998) or fail to appreciate the detrimental impact of a long retention interval on subsequent retrieval (e.g., Koriat, Bjork, Sheffer, \& Bar, 2004). In addition, the substantial improvement in resolution that occurs when predictions are made after a delay rather than immediately after an item's presentation (e.g., Dunlosky
\& Nelson, 1994; Nelson \& Dunlosky, 1991) likely reflects sensitivity to success or failure of covert retrieval (but see Kimball \& Metcalfe, 2003).

The present study is concerned with whether people can appreciate the impact of interference induced at retrieval. Several prior studies have investigated metacognition under conditions of interference, typically by eliciting item-by-item predictions for paired associates at encoding (e.g., Eakin, 2005; Leibert \& Nelson, 1998; Maki, 1999; Metcalfe, Schwartz, \& Joaquim, 1993). For example, Maki had participants study pairings of three-digit numbers (the cue) and nouns (the target) in an initial encoding phase. This was followed by a second encoding phase in which participants again studied digit-noun pairs. Some cues were repeated and paired with different targets, whereas other pairs consisted of entirely new cue-target pairings. Finally, stimuli studied in the first list were shown again, and participants were asked to make a judgment of learning (JOL) for each target, rating the likelihood of recalling the target on a subsequent test. The results showed that JOLs were sensitive to interference, with lower predictions for cues studied with a different target in the second phase than for pairs that differed entirely across the first two study phases (see Leibert \& Nelson, 1998, for a similar pattern in a retroactive interference paradigm). This finding contrasts with data reported by Metcalfe et al.,

M. G. Rhodes, matthew.rhodes@colostate.edu 
who observed that feeling-of-knowing judgments were sensitive to the number of times a cue was studied. For example, participants in their study made similar predictions following two presentations of the same cue-target pair $(\mathrm{A}-\mathrm{B}$, then $\mathrm{A}-\mathrm{B})$ and following two presentations of the same cue paired with a different target (i.e., A-B, then A-D), despite poorer recall performance on A-B, A-D pairs. Likewise, Chandler (1994) reported data from experiments in which participants studied sets of pictures. Either immediately following or just prior to study, participants also viewed additional pictures, some of which were related to the studied set. Results across a number of experiments showed that studying related pictures increased confidence but decreased recognition accuracy for target items (see also Eakin, 2005).

Thus, prior findings suggest that participants may be sensitive to interference (e.g., Maki, 1999) or may base predictions largely on cue familiarity (e.g., Chandler, 1994; Metcalfe et al., 1993; see also Glenberg, Sanocki, Epstein, \& Morris, 1987; Reder, 1987). However, these conclusions have almost entirely been drawn from studies in which predictions were made during encoding, and the principal manipulation was one related to encoding conditions. Thus, it remains unclear how people assess cues at retrieval when making predictions regarding memory performance. In the present study, we examined participants' sensitivity to a source of interference that occurs at retrieval - namely, part-set cuing.

Part-set cuing is a counterintuitive phenomenon, first documented by Slamecka (1968; see also Roediger \& Neely, 1982; Roediger, Stellon, \& Tulving, 1977; Rundus, 1973), in which participants are less likely to recall a list of studied items if presented with a subset of that list either prior to or during retrieval. That is, proportionally, participants recall more when engaging in a free recall task than when cued with a subset of the studied items (see Nickerson, 1984, for a review). Such findings are important to theories of memory, showing that recall can be a self-limiting process (Roediger, 1978), acting in such a way as to prevent access to certain categories at test if competing category cues are used to recall other material. Furthermore, part-set cuing places boundary conditions on theories (i.e., encoding specificity) that hold that reinstating previously studied items should benefit recall. Part-set cuing has been extended to semantic memory tasks, such as recalling states (e.g., Brown, 1968; Karchmer \& Winograd, 1971) and non-memory-related tasks (Peynircioğlu, 1987), and has been used as a method of understanding false memories (e.g., Reysen \& Nairne, 2002), aging (Marsh, Dolan, Balota, \& Roediger, 2004), and individual differences in working memory span (Cokely, Kelley, \& Gilchrist, 2006). However, it is not known whether people are aware of the degree to which recall can act in a self-limiting manner. In particular, most naive or common sense theories of memory suggest that almost any type of cue from a previously studied list would enhance recall. Awareness of the potential detrimental effects of part-set cues would be important in a variety of circumstances (e.g., studying for an exam, remembering an event, or learning the names of students in one's class), because such awareness would signal one to exercise metacognitive control (cf. Nelson \& Narens, 1990) and to adjust strategies accordingly in order to cope with interference.

In recent theories of part-set cuing, researchers have assumed that part-set cues decrease access to noncued items, either through an inhibitory process (e.g., Aslan, Bäuml, \& Grundgeiger, 2007) or by disrupting encoding or retrieval strategies (Basden, Basden, \& Stephens, 2002; Cokely et al., 2006; Dodd, Castel, \& Roberts, 2006). Thus, in the present study, we ask: Can participants predict interference engendered by part-set cues? Consistent with an accessibility account (Koriat, 1993, 1995), prior data (Maki, 1999; see also Schreiber \& Nelson, 1998) indicate that under some circumstances, participants can predict factors that limit access to studied information (but see Eakin, 2005). Thus, an accessibility account would hold that predictions of performance in a part-set cuing task should be sensitive to interference (i.e., decreased accessibility to studied items) created by part-set cues, with lower predictions of performance under part-set cuing than under free recall conditions. However, if participants base predictions solely on the familiarity of the cues presented (e.g., Metcalfe et al., 1993), part-set cuing may lead to predictions of higher performance for part-set cuing than for free recall. That is, a cue familiarity account would hold that participants should use the familiarity of previously studied part-set cues as a basis for predictions, resulting in predictions of better performance under partset cuing than under free recall. ${ }^{1}$

We investigated these possibilities in three experiments. In Experiment 1, we examined predictions of part-set cuing in a semantic memory task that has been commonly used in other part-set cuing experiments. Specifically, participants in Experiment 1 were asked to provide predictions of the number of states of the United States that they could recall, given either no cues or a list of 25 randomly selected states (cf. Brown, 1968). In Experiment 2, we examined whether experience with part-set cuing (i.e., several study-test opportunities with part-set cues) can inform subsequent predictions of memory performance in an episodic memory task. To anticipate, Experiment 2 demonstrated that with prior experience, participants could predict interference engendered by part-set cues. Thus, in Experiment 3, we examined whether knowledge acquired about part-set cuing would transfer to a different part-set cuing task, providing a stronger demonstration that participants can learn about factors that diminish accessibility to information at retrieval and apply this knowledge to a new learning situation.

\section{EXPERIMENT 1}

In Experiment 1, participants made predictions regarding the number of states of the United States that they could recall if given either no cues (free recall) or a list of 25 randomly selected states (part-set cuing). Our procedure differs slightly from others (e.g., Brown, 1968; Karchmer \& Winograd, 1971) in that participants did not study a subset of the states prior to engaging in the re- 
call task. Instead, we attempted to examine predictions in the context of part-set cues without any possible influence of a prior study episode. On the basis of prior work (Brown, 1968), we expected that participants given a list of 25 randomly chosen states would recall fewer states, proportionally, than would participants charged with recalling all 50 states. If the familiarity of cues from the to-be-recalled list is used as a basis for predictions (cf. Metcalfe et al., 1993), participants given 25 randomly selected states should exhibit high levels of overconfidence and higher predictions than would participants in the free recall condition. In contrast, an accessibility account (e.g., Koriat, 1993) would suggest that if participants are sensitive to interference engendered by the part-set cues, predictions should reflect such interference and should, thus, be lower for the part-set cuing condition than for the free recall condition.

Note that in Experiment 1 and in each of the other experiments reported in the present study, we used global (i.e., aggregate) predictions of memory performance rather than item-by-item predictions, such as JOLs. Global predictions were used because participants could not be aware of which items were part-set cues or items to be recalled until just prior to testing. That is, judgments made item by item could not possibly be expected to take into account interference engendered by part-set cues, because the status of an item was not apparent until retrieval, necessitating the use of global predictions.

\section{Method \\ Participants. Fifty Colorado State University psychology stu- dents participated for partial course credit. Participants were tested individually or in groups of up to 8 . \\ Design. A 2 (condition: free recall, part-set cuing) $\times 2$ (measure: prediction, recall) mixed-factor design was used, with condition manipulated between participants and measure manipulated within participants \\ Materials and Procedure. Participants were randomly assigned either to engage in free recall of the 50 states (the free recall condi- tion) or to attempt to recall half of the 50 states while avoiding intru- sions from a list of 25 randomly selected states (the part-set cuing condition). Participants in the free recall condition were given a sheet of paper with instructions asking them to write down the num- ber of states that they predicted they could remember if given $4 \mathrm{~min}$ for recall. Participants in the part-set cuing condition were given a sheet of paper with a list of 25 randomly selected states. ${ }^{2}$ They were allowed to briefly examine this list and were then asked to write down their prediction of how many states they could recall (out of 25 ) if allotted $4 \mathrm{~min}$. Following their prediction, participants started the recall task at the behest of the experimenter and engaged in re- call for $4 \mathrm{~min}$. Participants in the free recall condition were asked to recall as many of the 50 states as possible, whereas participants in the part-set cuing condition were asked to recall as many of the remaining 25 states as possible. Following the task, all participants were debriefed and thanked for their participation.}

\section{Results}

An alpha level of .05 was used for all statistical tests reported. The dependent variable for this and subsequent analyses was the proportion of states recalled and predicted out of the total possible ( 50 for the free recall condition, 25 for the part-set cuing condition). ${ }^{3}$ As is shown in Figure 1, predictions (solid lines) did not differ between conditions, but the proportion of states recalled (broken lines) did. These data were analyzed in a 2 (condition: free recall, part-set cuing) $\times 2$ (measure: prediction, recall) mixedfactor ANOVA. Results showed that, overall, predictions $(M=.63)$ did not differ from recall $(M=.62)(F<1)$, nor did the two conditions differ $[F(1,48)=1.42, p=.24$, $\left.\eta_{\mathrm{p}}^{2}=.03\right]$. However, a reliable condition $\times$ measure interaction was present $\left[F(1,48)=4.60, \eta_{\mathrm{p}}^{2}=.09\right]$. Specifically, whereas predictions did not differ between the two groups $(F<1)$, participants in the free recall condition recalled a significantly greater proportion of states than did participants in the part-set cuing condition $[F(1,48)=$ $\left.5.25, \eta_{\mathrm{p}}^{2}=.10\right]$. Thus, a part-set cuing effect was present, but participants did not predict this, which is evident in the fact that predictions did not differ between conditions. Because of our interest in the correspondence between predictions and recall performance (i.e., calibration), we also examined calibration within each condition. These data showed that predictions did not reliably differ from recall performance for participants in the free recall condition $\left[F(1,24)=1.25, p=.28, \eta_{\mathrm{p}}^{2}=.05\right]$ but that participants marginally overestimated performance in the part-set cuing condition $\left[F(1,24)=3.56, p=.07, \eta_{\mathrm{p}}^{2}=.13\right]$.

\section{Discussion}

The results from Experiment 1 suggest that participants' predictions were entirely insensitive to the manipulation of part-set cuing. Indeed, although part-set cuing resulted in a reliable decrement in recall performance, predictions did not differ at all between the free recall and part-set cuing conditions. Neither theories predicated on sensitivity to the accessibility of information (e.g., Koriat, 1993; Maki, 1999) nor theories based on cue familiarity (e.g., Metcalfe et al., 1993) would anticipate this result. That is, if participants were sensitive to diminished accessibility wrought by part-set cues, predictions should have been lower for the part-set cuing condition than for the free recall condition. In addition, if cue familiarity were a basis for prediction, then predictions should have been higher

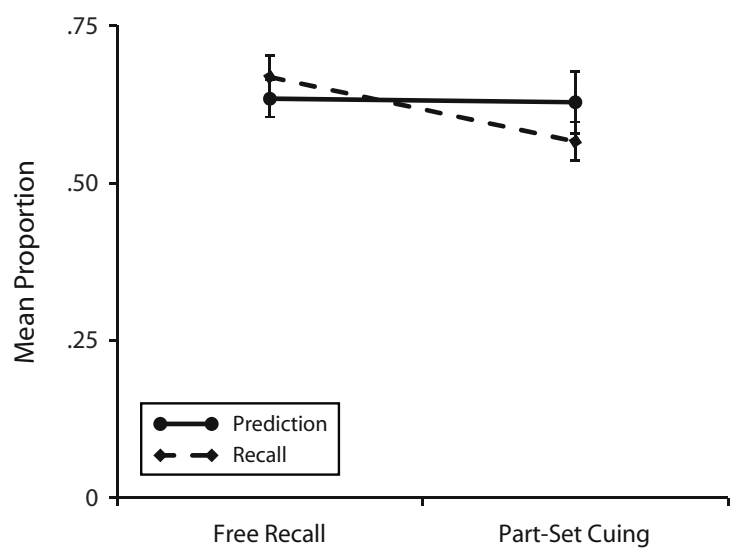

Figure 1. Predicted and actual recall performance for the partset cuing and the free recall conditions in Experiment 1. Error bars reflect standard errors of the means in all figures. 
for the part-set cuing than for the free recall condition, because the part-set cues were similar to the set of items to be recalled.

Thus, it is unclear how current theory could account for the data in Experiment 1. It may be that the presentation of part-set cues is sufficiently novel that participants had little information to guide performance and thus made predictions that entirely neglected the presence of cues at retrieval. This begs the question of whether participants can learn to predict the interference engendered by part-list cues. Given that it would not be ideal to have participants engage in recall from the same set of items (e.g., states of the U.S.) several times, in Experiment 2, we employed an episodic memory task and provided participants with several successive opportunities (i.e., experience with retrieval conditions) in order to make predictions of performance after exposure to part-set cues. In addition, employing an episodic memory task allowed us to examine whether the discrepancy between predicted and actual recall performance generalizes beyond semantic memory tasks and provides a stronger test of a cue familiarity account. For example, presenting a subset of 25 states, although they were from the same class of items as the to-be-remembered set, may not have been sufficient to engender familiarity in the same manner as recently studied items would. Thus, using an episodic memory task provides a more stringent test of a cue familiarity account of predictions with part-set cuing.

\section{EXPERIMENT 2}

Participants in Experiment 2, as in Experiment 1, either were exposed to part-set cues prior to recall or engaged in free recall. Our particular interest was in determining whether participants could adjust predictions of performance accurately in response to previous experience with part-set cues. To do so, we employed an episodic memory task in which participants studied a list of 20 unrelated words and then attempted to recall either all of the words or a subset of the words after exposure to part-set cues. Participants engaged in the same free recall or part-set cuing task three times, with each recall attempt preceded by a unique list of words. That is, the items to be recalled on each occasion changed, but the task remained the same. With such experience, participants may learn that part-set cues interfere with recall and, thus, may adjust predictions accordingly. Consistent with this idea, Koriat and Bjork (2006a) observed enhancements in calibration when participants were exposed to multiple study-test cycles (see also Koriat, 1997). Likewise, Castel (2008) demonstrated that predictions became sensitive to serial position effects when participants had prior experience with the availability of serial position information at retrieval. Thus, under some conditions, participants can with experience with retrieval conditions learn to adaptively adjust predictions.

If participants can learn from prior experience with part-set cuing, in Experiment 2, they should become more adept at predicting performance and better calibrated with each successive recall attempt. Such data would suggest that with experience, participants can become sensitive to factors that result in interference, consistent with an accessibility account. As was previously noted, Experiment 2 also permits a stronger test of the cue familiarity account. That is, in contrast to Experiment 1, the part-set cues employed in Experiment 2 were part of a recently studied list and, thus, should be highly familiar. If cue familiarity drives predictions, participants should predict better recall in the part-set cuing condition than in the free recall condition. In contrast, if participants become sensitive to diminished access to target information created by part-set cuing, predictions should be lower in the part-set cuing than in the free recall condition.

\section{Method}

Participants. Sixty Colorado State University psychology students participated for partial course credit. Participants were tested individually.

Design. A 2 (condition: free recall, part-set cuing) $\times 2$ (measure: prediction, recall) $\times 3$ (trial: $1,2,3$ ) mixed-factor design was used, with condition manipulated between participants and measure and trial manipulated within participants.

Materials. The materials consisted of a set of 60 unrelated nouns. This set of 60 nouns was divided into three sets of 20 items, equated for Kučera and Francis (1967) frequency $(M=42.37)$, number of letters $(M=5.58)$, and number of syllables $(M=1.70)$. Each set of 20 items served equally often as a study list in each trial of the experiment. Furthermore, each set of 20 items was randomly split into subsets of 10 items to serve as part-list cues. Each subset of 10 items was equated on the dimensions previously noted and served equally often as the cued or noncued items in the part-set cuing condition.

Procedure. Participants were randomly assigned to either the free recall condition or the part-set cuing condition. The participants in each condition first studied a list of 20 words in anticipation of a test of memory. The items were presented in white, lowercase letters (Arial 40-point font) in the center of a black background on a computer monitor. Items were presented for $3 \mathrm{sec}$ each, with a $500-\mathrm{msec}$ interstimulus interval, in a fixed random order. At the conclusion of the study list, the participants in the free recall condition were given a set of addition, subtraction, and multiplication problems to work on for $30 \mathrm{sec}$. The participants in the part-set cuing condition were shown half of the items that they had studied and were asked to examine each item and to identify whether it had been presented in the beginning, middle, or end of the study list (cf. Cokely et al., 2006). This was done in order to ensure that participants attended to the part-set cues, and took approximately $30 \mathrm{sec}$ to complete.

Following these interpolated tasks, all of the participants were asked to predict the number of words that they would be able to recall in $1.5 \mathrm{~min}$, with participants in the free recall condition making this estimate out of 20 words possible and participants in the part-set cuing condition making this estimate out of 10 words possible. They were then given $1.5 \mathrm{~min}$ to recall as many items as possible. Participants wrote both their prediction and the items they could recall on a provided sheet. For participants in the part-set cuing condition, the list of part-set cues was always present on a computer screen directly in front of them, and the participants were instructed to avoid any intrusions from this list. The remainder of the experiment included two more phases, identical to this first phase, except that in each phase, participants studied, made predictions, and attempted to recall a unique set of words. At the conclusion of the experiment, all of the participants were debriefed and thanked for their participation.

\section{Results}

Predictions and recall performance are presented in Figures 2A (free recall) and 2B (part-set cuing) and reflect proportions based on the total number of items possible in each condition. Before examining the relation 


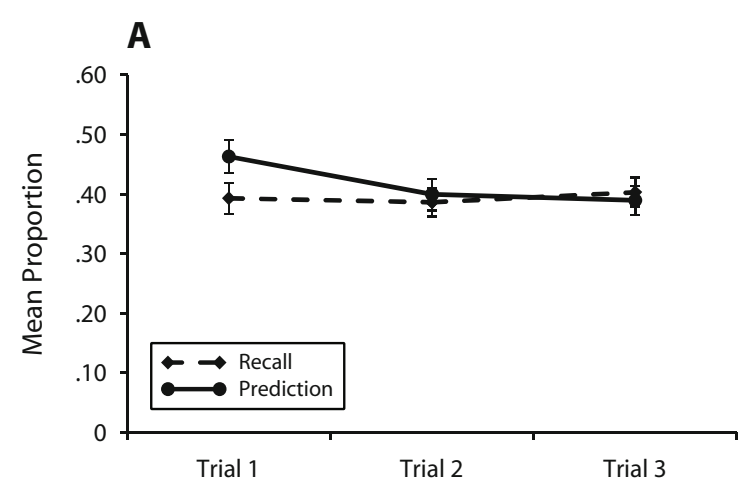

B

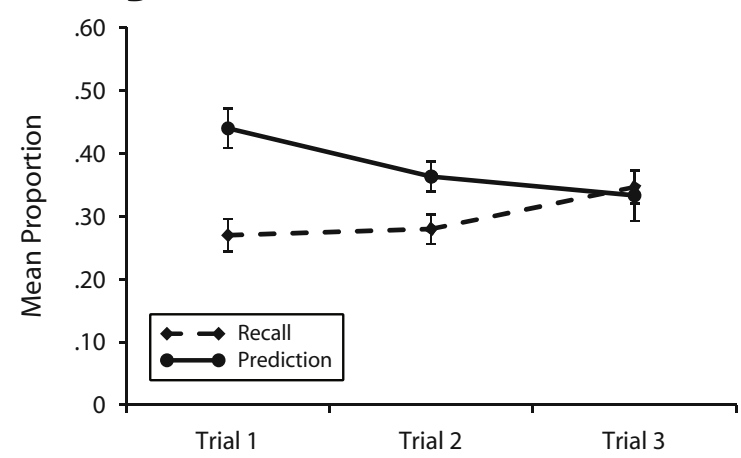

Figure 2. (A) Predicted and actual recall performance as a function of list order (trial) for participants in the free recall condition in Experiment 2. (B) Predicted and actual recall performance as a function of list order (trial) for participants in the part-set cuing condition in Experiment 2.

between predictions and performance, we first checked that our manipulation of part-set cuing produced a decrement in recall, analyzing the proportion of items recalled in a 2 (condition: free recall, part-set cuing) $\times 2$ (trial: $1,2,3)$ mixed-factor ANOVA. The results showed that recall in the free recall condition $(M=.39)$ was superior to that in the part-set cuing condition $(M=.30)[F(1,58)=$ $\left.9.58, \eta_{\mathrm{p}}^{2}=.14\right]$. Thus, our part-set cuing manipulation effectively diminished recall, permitting us to examine the relation between predicted and actual recall performance across conditions.

These data were analyzed in a 2 (measure: recall, estimate) $\times 3$ (trial: $1,2,3) \times 2$ (condition: free recall, part-set cuing) mixed-factor ANOVA. The results showed that participants' predictions $(M=.40)$ reliably exceeded actual recall performance $(M=.35)[F(1,58)=13.66$, $\left.\eta_{\mathrm{p}}^{2}=.19\right]$. In addition, performance varied between conditions $\left[F(1,58)=6.30, \eta_{\mathrm{p}}^{2}=.10\right]$ and differed marginally across trials $\left[F(2,116)=2.71, p=.07, \eta_{\mathrm{p}}^{2}=.05\right]$. More important, several interactions were present. In particular, a reliable measure $\times$ condition interaction was evident $\left[F(1,58)=4.11, \eta_{\mathrm{p}}^{2}=.07\right]$. This interaction reflects the fact that, overall, predictions $(M=.42)$ did not reliably differ from recall $(M=.39)$ for the free recall condition $\left[F(1,29)=1.79, p=.19, \eta_{\mathrm{p}}^{2}=.06\right]$. However, for the part-set cuing condition, predictions $(M=.38)$ reliably exceeded recall $(M=.30)\left[F(1,29)=13.43, \eta_{\mathrm{p}}^{2}=.32\right]$. A measure $\times$ trial interaction was also present, since, overall, predictions $\left[F(2,116)=17.76, \eta_{\mathrm{p}}^{2}=.23\right]$, but not recall performance $\left[F(2,116)=2.16, p=.12, \eta_{\mathrm{p}}^{2}=.04\right]$, differed across trials. The triple interaction of measure, trial, and condition was not reliable $[F(2,116)=1.84, p=$ $\left..16, \eta_{\mathrm{p}}^{2}=.03\right]$.

Because of our interest in calibration, we also examined the difference between predicted and actual recall performance for each trial within each condition. Results showed that, for the free recall condition, participants reliably overestimated performance on Trial $1[F(1,58)=$ $\left.5.86, \eta_{\mathrm{p}}^{2}=.17\right]$. However, no difference was evident between predictions and recall for Trials 2 and $3\left(F_{\mathrm{S}}<1\right)$. A different pattern was evident for the part-set cuing condition. In that condition, participants overestimated performance on Trial $1\left[F(1,58)=29.13, \eta_{\mathrm{p}}^{2}=.50\right]$ and on Trial $2\left[F(1,58)=10.39, \eta_{\mathrm{p}}^{2}=.26\right]$. Only by Trial $3 \mathrm{did}$ participants' predictions in the part-set cuing condition accurately anticipate recall performance $(F<1)$.

\section{Discussion}

The results from Experiment 2 indicate that, for participants in the free recall condition, estimates were well calibrated (i.e., there was little discrepancy between predicted and actual recall performance) by Trial 2. In contrast, participants in the part-set cuing condition did not achieve such calibration until Trial 3. This result suggests that, with experience, participants learned to anticipate the interference created by part-set cues, consistent with accounts that suggest that predictions are sensitive to the accessibility of to-be-remembered information (e.g., Maki, 1999). Such data are inconsistent with a cue familiarity account. That is, because part-set cues had been recently studied (and were thus familiar), a cue familiarity account would hold that predictions in the part-set cuing condition should exceed those in the free recall condition, in which participants were not exposed to recently studied items prior to retrieval. Instead, predictions did not differ between the part-set cuing and the free recall conditions and were reduced across trials, consistent with an accessibility account.

The fact that predictions became sensitive to performance by Trial 3 begs the question of whether participants indeed learned that part-set cues diminish access to previously studied information. Thus, we asked in Experiment 3 whether knowledge gained from practice with part-set cuing transfers to a somewhat different part-set cuing task.

\section{EXPERIMENT 3}

Findings from Experiment 2 suggested that participants were able to learn about the disruptive effects of part-set cues through several successive study retrieval opportunities. For example, by Trial 3, participants in the partset cuing condition were well calibrated and exhibited no difference between predictions and recall. This result contrasts sharply with the high level of overconfidence 
evident for participants in the part-set cuing condition on Trial 1. Thus, one might conclude that participants in the part-set cuing condition learned about the nature of part-set cues and adjusted predictions accordingly. Alternatively, participants may have simply reflected on recall performance in the prior trial and adjusted predictions, irrespective of whether part-set cues were present. In order to test these possibilities, we examined whether participants would become sensitive to part-set cues in a task that differed somewhat from prior part-set cuing tasks.

In Experiment 3, we included a transfer task immediately following experience with part-set cuing or free recall (cf. Koriat \& Bjork, 2006b). Specifically, participants in Experiment 3 first did a succession of either part-set cuing or free recall tasks, identical to the tasks used in Experiment 2. Thus, the first part of Experiment 3 was essentially a replication of Experiment 2. However, immediately after completing the third study-test trial, participants studied a 40-word list (twice as long as their previous study lists) and then completed either a part-set cuing or free recall task. This combination of conditions ensured that half of the participants who originally performed several part-set cuing tasks did either a part-set cuing or a free recall task at transfer. Likewise, participants who originally performed several free recall tasks did either a part-set cuing or a free recall task at transfer. We expected that if participants could learn that part-set cues disrupt performance, participants who originally performed several part-set cuing tasks would exhibit more accurate predictions on the part-set cuing transfer task than would participants who originally did free recall tasks. However, the improvement in performance may be confined to the specific, 20-word lists employed on the original tasks. If that is the case, we would not expect to observe any transfer when participants are given a part-set cuing task for the 40-word list.

\section{Method}

Participants. Forty-eight Colorado State University psychology students participated for partial course credit. Participants were tested individually.

Design. A 2 (initial tasks: free recall, part-set cuing) $\times 2$ (transfer task: free recall transfer, part-set cuing transfer) $\times 2$ (measure: prediction, recall) $\times 3$ (trial: $1,2,3$ ) mixed-factor design was used, with initial tasks and transfer task manipulated between participants and measure and trial manipulated within participants.

Materials. The materials for the initial set of part-set cuing and free recall tasks were identical to those used for the part-set cuing and free recall conditions of Experiment 2. Items for the transfer task consisted of a set of 40 unrelated nouns taken from the same general set as the items used in Experiment 2. These items were equated with those used in the original part-set cuing and free recall tasks in terms of Kučera and Francis (1967) frequency $(M=40.03)$, number of letters $(M=5.60)$, and number of syllables $(M=1.68)$. In addition, the set of 40 items used for the transfer task was randomly split into two subsets of 20 items to serve as part-list cues. Each subset of 20 items was equated on the dimensions previously noted and served equally often as the cued or noncued items in the part-set cuing transfer condition.

Procedure. Participants were randomly assigned to either the free recall or the part-set cuing condition for their initial tasks and to the free recall or part-set cuing condition for their transfer task. The initial part-set cuing or free recall tasks consisted of three study-test trials that used the same procedure as that used in Experiment 2. Immediately following the third study-test trial, participants proceeded to the transfer phase of the experiment. Participants were instructed that they would study a list that would be longer than the lists they had studied previously. The procedure for this study phase was identical to that used previously, with the exception that participants studied 40 instead of 20 words. At the conclusion of the transfer study list, participants in the free recall transfer condition were given a set of addition, subtraction, and multiplication problems to work on for $60 \mathrm{sec}$. Participants in the part-set cuing transfer condition were shown half of the items that they had studied and were asked to examine each item and to identify whether it had been presented in the beginning, middle, or end of the study list (cf. Cokely et al., 2006). This task took approximately $60 \mathrm{sec}$ to complete.

Following these interpolated tasks, all of the participants were asked to predict how many words they would be able to remember in $3 \mathrm{~min}$, with participants in the free recall condition making this prediction out of 40 words possible and participants in the part-set cuing condition making this prediction out of 20 words possible. Participants were then given 3 min to recall as many items as possible. All other aspects of the test procedure were the same as those in Experiment 2.

\section{Results}

Predictions and recall performance are presented in Figures 3A (free recall) and 3B (part-set cuing). As in Experiment 2 , we first examined recall performance to determine whether our manipulation of part-set cuing produced a decrement in recall, analyzing the proportion of items recalled in a 2 (condition: part-set cuing, free recall) $\times$ 3 (trial: $1,2,3$ ) mixed-factor ANOVA. Overall, recall in the free recall condition $(M=.46)$ was superior to that in the part-set cuing condition $(M=.33)[F(1,46)=8.57$, $\left.\eta_{\mathrm{p}}^{2}=.16\right]$. Thus, our part-set cuing manipulation was effective, permitting us to examine the relation between predictions and actual recall performance across conditions.

Overall performance. These data were first analyzed in a 2 (measure: prediction, recall) $\times 3$ (trial: $1,2,3) \times$ 2 (initial tasks: free recall, part-set cuing) mixed-factor ANOVA. Results showed that participants' predictions $(M=.44)$ reliably exceeded recall performance $(M=.39)$ $\left[F(1,46)=6.20, \eta_{\mathrm{p}}^{2}=.12\right]$. In addition, performance varied by initial task conditions $\left[F(1,46)=6.50, \eta_{\mathrm{p}}^{2}=.12\right]$ but did not differ across trials $(F<1)$. More important, several interactions were present. In particular, a reliable measure $\times$ initial tasks interaction was evident $[F(1,46)=$ $\left.4.54, \eta_{\mathrm{p}}^{2}=.09\right]$. This interaction reflects the fact that, overall, predictions $(M=.46)$ did not differ from recall $(M=$ .47) for the free recall condition $(F<1)$. However, for the part-set cuing condition, predictions $(M=.41)$ reliably exceeded recall $(M=.33)\left[F(1,22)=12.13, \eta_{\mathrm{p}}^{2}=.35\right]$. A measure $\times$ trial interaction was also present $[F(2,92)=$ $\left.5.23, \eta_{\mathrm{p}}^{2}=.10\right]$, since predictions differed across trials $\left[F(2,92)=5.53, \eta_{\mathrm{p}}^{2}=.11\right]$, but recall did not $[F(2,92)=$ $\left.1.21, p=.30, \eta_{\mathrm{p}}^{2}=.10\right]$. The triple interaction of measure, trial, and initial tasks was not reliable $(F<1)$.

As in Experiment 2, because of our interest in calibration, we examined the difference between predicted and actual recall performance by trial within each condition. Results showed that, in the free recall condition, predictions did not reliably differ from recall on Trial $1[F(1,22)=3.46, p=.08$, $\left.\eta_{\mathrm{p}}^{2}=.13\right]$. The same pattern was evident on Trials $2(F<1)$ 


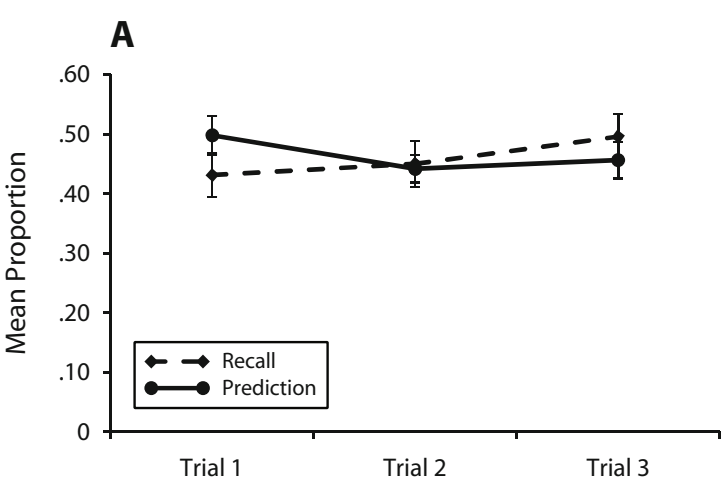

B

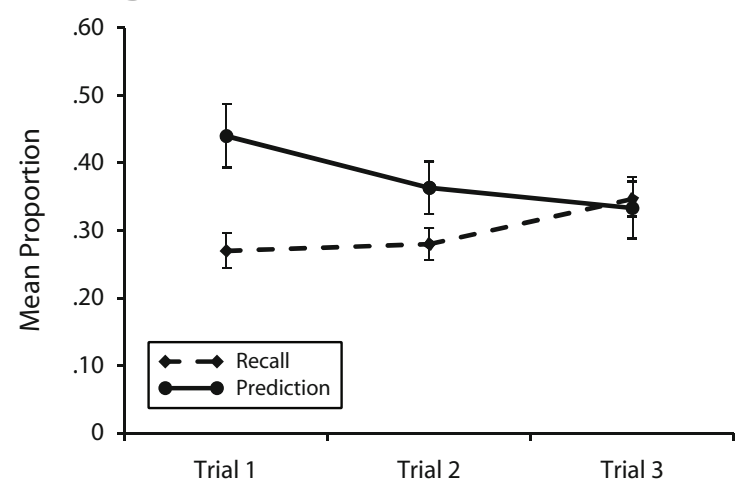

Figure 3. (A) Predicted and actual recall performance as a function of list order (trial) for participants in the free recall condition in Experiment 3. (B) Predicted and actual recall performance as a function of list order (trial) for participants in the part-set cuing condition in Experiment 3.

and $3\left[F(1,46)=2.04, p=.17, \eta_{\mathrm{p}}^{2}=.08\right]$. For the part-set cuing condition, participants' predictions overestimated recall on Trials $1\left[F(1,22)=5.58, \eta_{\mathrm{p}}^{2}=.20\right]$ and $2[F(1,46)=$ $\left.13.32, \eta_{\mathrm{p}}^{2}=.37\right]$. However, no difference was evident between predictions and recall by Trial $3(F<1)$.

Thus, these data suggest that, for participants in the free recall condition, estimates were relatively well calibrated (i.e., there was little discrepancy between predicted and actual recall performance) by Trial 2 , whereas participants in the part-set cuing condition did not meet this criterion until Trial 3. We next turned to the question of whether performance on the initial part-set cuing or free recall tasks transferred to a somewhat different task.

Part-set cuing at transfer. Predictions and recall for the transfer task are presented in Figures 4A (partset cuing transfer) and 4B (free recall transfer). We first examined recall performance across transfer conditions to determine whether our manipulation of part-set cues was effective. Results showed that recall in the free recall condition $(M=.31)$ was superior to that in the part-set cuing condition $(M=.15)\left[F(1,46)=17.86, \eta_{\mathrm{p}}^{2}=.28\right]$. Thus, our part-set cuing manipulation was effective, permitting us to examine transfer across conditions.
Overall transfer performance. Performance on the transfer tasks was examined in a 2 (measure: prediction, recall) $\times 2$ (initial task: free recall, part-set cuing) $\times$ 2 (transfer task: free recall transfer, part-set cuing transfer) mixed-factor ANOVA. Results showed that participants' predictions $(M=.28)$ reliably exceeded actual recall performance $(M=.23)\left[F(1,44)=9.21, \eta_{\mathrm{p}}^{2}=.17\right]$. Performance varied reliably between transfer task conditions $\left[F(1,44)=5.93, \eta_{\mathrm{p}}^{2}=.12\right]$ but did not differ between initial task conditions $\left[F(1,44)=3.06, p=.09, \eta_{\mathrm{p}}^{2}=.07\right]$. More importantly, several interactions were present. In particular, a reliable measure $\times$ transfer task interaction was evident $\left[F(1,44)=13.97, \eta_{\mathrm{p}}^{2}=.24\right]$, which was subsumed by a reliable three-way interaction of measure, initial tasks, and transfer task $\left[F(1,44)=6.64, \eta_{\mathrm{p}}^{2}=.13\right]$. Follow-up tests were conducted in order to explore this interaction by examining performance in each transfer condition.

Part-set cuing transfer performance. Performance in the part-set cuing transfer condition was analyzed in a 2 (measure: prediction, recall) $\times 2$ (initial task: free recall, part-set cuing) mixed-factor ANOVA. The results showed that estimates $(M=.27)$ reliably exceeded actual recall performance $(M=.15)\left[F(1,22)=20.44, \eta_{\mathrm{p}}^{2}=.48\right]$. Performance did not vary by initial task $[F(1,44)=1.90$, $\left.p=.18, \eta_{\mathrm{p}}^{2}=.08\right]$, but a reliable measure $\times$ initial task interaction was present $\left[F(1,22)=6.67, \eta_{\mathrm{p}}^{2}=.23\right]$. In particular, whereas recall did not differ between conditions, $(F<1)$, participants who first did part-set cuing made reliably lower predictions than did participants who first did free recall $\left[F(1,22)=4.38, \eta_{\mathrm{p}}^{2}=.17\right]$. Thus, participants who first did part-set cuing exhibited more sensitivity to part-set cuing at transfer than did participants who initially did free recall.

Free recall transfer condition. Performance in the free recall transfer condition was analyzed in a 2 (measure: prediction, recall) $\times 2$ (initial task: free recall, part-set cuing) mixed-factor ANOVA. Results showed that estimates $(M=.29)$ did not differ from recall performance $(M=.30)$ $(F<1)$. Performance did not vary by first task $[F(1,22)=$ $\left.1.27, p=.27, \eta_{\mathrm{p}}^{2}=.05\right]$; neither did initial task interact with measure $(F<1)$. Follow-up tests confirmed that neither recall $\left[F(1,22)=1.90, p=.18, \eta_{\mathrm{p}}^{2}=.08\right]$ nor predictions $(F<1)$ differed between initial task conditions.

\section{Discussion}

The results from Experiment 3 replicated those of Experiment 2 . That is, predictions were initially better calibrated for the free recall condition than for the part-set cuing condition. However, with practice, differences in calibration between conditions were eliminated, since participants became sensitive to the detrimental effects of part-set cuing, consistent with an accessibility account. Moreover, performance on the transfer tasks suggests that participants who initially experienced part-set cuing were better able to predict their performance on a transfer task that also involved part-set cuing than were participants who initially did free recall. This occurred in conjunction with identical recall performance between the conditions. In contrast, there were no differences in performance (ei- 

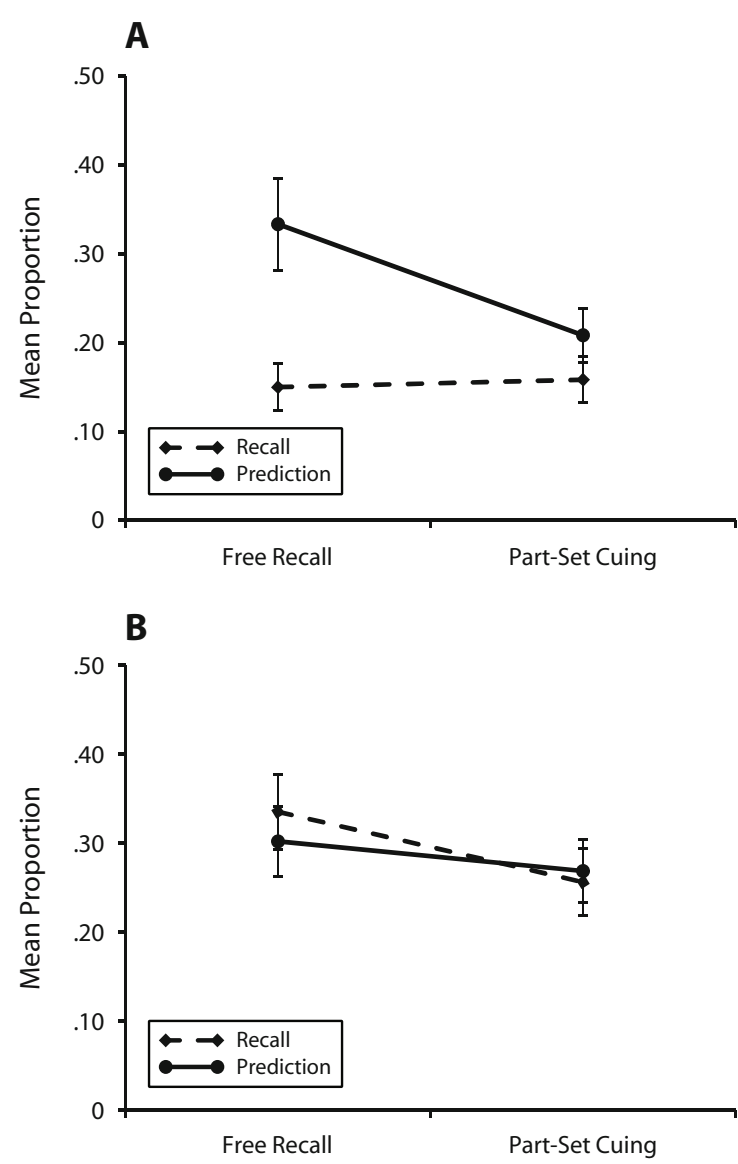

Figure 4. (A) Predicted and actual recall performance as a function of initial task for participants in the part-set cuing transfer condition in Experiment 3. (B) Predicted and actual recall performance as a function of initial task for participants in the free recall transfer condition in Experiment 3.

ther of recall or predictions) for the free recall transfer task. We examine the implications of these data and other issues in the General Discussion section.

\section{GENERAL DISCUSSION}

In the present study, we examined the extent to which participants' predictions of memory performance anticipate the detrimental effect of part-set cues on recall. In Experiment 1, we used a semantic memory task in which participants were charged with recalling states in the U.S., either under free recall instructions or after having been cued with 25 randomly selected states. Results showed that, although part-set cues led to a reliable decrement in recall as compared with the free recall condition, predictions were identical for the two groups. In Experiment 2, we investigated whether participants were similarly insensitive to part-set cues in an episodic memory task and whether, after several exposures to part-set cues, predictions would become more accurate. Those data suggested that although participants' predictions did not initially anticipate interference engendered by part-set cues, with experience, participants became well calibrated. For example, by Trial 3, participants in the part-set cuing condition made predictions that were consistent with recall.

Experiment 3 demonstrated that initial experience with part-set cuing transferred to a different part-set cuing task. In particular, predictions for participants who first did part-set cuing were more sensitive to interference engendered at retrieval by part-set cues than were participants who first did free recall. Thus, these data suggest that participants learned from prior experience with part-set cues and were able to transfer this knowledge to a somewhat different task. However, we do suggest some caution in this conclusion. In particular, the transfer task used in the present study retained many elements of the initial task, with only the length of the study list (and the number of part-set cues) changing from the initial task to the transfer task. A stronger test of transfer would likely involve changing more elements of the task. For example, after gaining experience with an episodic, list-learning version of the task, one could examine transfer to a semantic memory task, such as the states task used in Experiment 1 of the present study. If participants truly learned that part-set cues were detrimental to memory performance, they should make lower predictions of recall when exposed to part-set cues. However, for the present, it remains an open question whether transfer would also be observed for a task in which many elements change.

How do data reported in the present study cohere with extant accounts of predictions of performance under conditions of interference? One theory holds that predictions are made largely on the basis of the familiarity of the cues available (e.g., Metcalfe et al., 1993). Such an account would suggest that the provision of part-set cues, visible to participants when making predictions, would serve to elevate predictions of performance for the part-set cuing condition compared with the free recall condition. That is, given that participants viewed a subset of items from the to-be-recalled set when making predictions, a cue familiarity account would hold that this familiarity would lead to inflated levels of confidence. Results showed a consistent pattern of overconfidence for participants in part-set cuing conditions. This occurred both in a semantic memory task, with portions of the to-be-remembered set presented, and in an episodic memory task, with a subset of previously studied items presented as part-set cues. However, across experiments, predictions did not exceed the level of confidence evident for participants who were not provided with part-set cues, suggesting that familiarity cannot account for subsequent differences in predictions between the free recall and part-set cuing conditions (cf. Eakin, 2005).

Instead, we suggest that, with experience (i.e., in Experiments 2 and 3), participants' judgments were sensitive to diminished target accessibility due to interference from the cues. That is, consistent with an accessibility account, participants based their predictions on the amount of information coming to mind from the to-be-remembered set (Koriat, 1993). As noted previously, although theories of 
part-set cuing postulate different mechanisms, each suggests that part-set cues decrease access to noncued items (e.g., Aslan et al., 2007; Basden et al., 2002; Cokely et al., 2006). The increased sensitivity to part-set cues, evident after several trials in Experiments 2 and 3, may likewise reflect increased sensitivity to the fact that such cues diminish access to target information. Evidence for this diminished access may only come through experience (cf. Koriat, 1997), and thus only with experience did participants adjust predictions accordingly (Experiments 2 and 3) and transfer that knowledge to a different task (Experiment 3 ). Note also that this idea parallels other accounts, suggesting that predictions of memory performance can be sensitive to competition from extralist information (e.g., Schreiber, 1998; Schreiber \& Nelson, 1998).

Thus far, we have only reported data for cues that produce decrements in recall. We have also collected data suggesting that participants' predictions are insensitive to part-set cues even when such cues facilitate recall. For example, we tested participants using a variant of the partset cuing condition of Experiment 1. The difference was that participants were provided with the first 25 states of the U.S. in alphabetical order, rather than 25 randomly selected states (cf. Basden et al., 2002). As in Experiment 1, participants made predictions of their performance prior to recall. The results showed that participants experienced facilitation of recall performance in response to such cues, recalling a large proportion $(M=.72, S E=.03)$ of the noncued states. However, participants' mean predictions $(M=.58, S E=.03)$ revealed strong levels of underconfidence $[t(24)=4.71, p<.001]$. Therefore, when initially exposed to part-set cues, participants may not appreciate those cues that produce decrements or benefits in performance.

The present conclusions have implications beyond a laboratory context. That is, there may be situations in which being provided with cues or hints to previously learned information might be detrimental to recall. Awareness of such situations would seem to be of some benefit. For example, in the context of eyewitness testimony, the provision of a subset of cues might impair memory, as compared with questions asking for more structured recall (e.g., from the beginning to the end of an event). In the context of education, an awareness of the degree to which cues aid or hinder memory would likewise be helpful. For example, if a student were studying for an upcoming chemistry test and learned the periodic table of elements in order, cuing with a random subset of elements might potentially disrupt memory performance. Being aware that such cuing is detrimental to performance might motivate the learner to exercise control (cf. Nelson \& Narens, 1990) and to engage in further study, perhaps using a variety of strategies. In a broader context, understanding those factors, including part-set cuing, that interfere with retrieval can allow the learner to adjust strategies accordingly and can make learners aware of how cues can facilitate recall in some cases but play a detrimental role in others.

Overall, results from the present study are consistent with the idea that participants do not always appreciate factors that interfere with performance but can adjust their predictions with experience (cf. Benjamin, 2003; Castel, 2008; Koriat \& Bjork, 2006a). These data support theories suggesting that predictions are made on the basis of the accessibility of information coming to mind rather than of the familiarity of cues available to the rememberer. Future work would benefit from further examination of predictions under conditions that hinder or facilitate memory performance, specifically examining interference and the match between cues available at encoding and those present at test. For now, we suggest that the present study indicates that people are not always aware of factors at retrieval that can hinder performance.

\section{AUTHOR NOTE}

We thank Jeffrey Boman, Courtney Sanchez, Ana Senior, Haley Smith, Jessica Sullenberger, Michelle Thompson, and Kellene Wells for assistance with data collection and Colleen Kelley, Bob Bjork, Elizabeth Bjork, and Roddy Roediger for insight and helpful comments at various stages of this work. Correspondence concerning this article should be addressed to M. G. Rhodes, Department of Psychology, Colorado State University, Fort Collins, CO 80523-1876 (e-mail: matthew.rhodes@ colostate.edu).

\section{REFERENCES}

Arbuckle, T. Y., \& Cuddy, L. L. (1969). Discrimination of item strength at time of presentation. Journal of Experimental Psychology, 81, 126-131.

Aslan, A., BäumL, K.-H., \& Grundgeiger, T. (2007). The role of inhibitory processes in part-list cuing. Journal of Experimental Psychology: Learning, Memory, \& Cognition, 33, 335-341.

Basden, B. H., Basden, D. R., \& Stephens, J. P. (2002). Part-set cuing of order information in recall tests. Journal of Memory \& Language, 47, 517-529.

Benjamin, A. S. (2003). Predicting and postdicting the effects of word frequency on memory. Memory \& Cognition, 31, 297-305.

Benjamin, A. S., BJork, R. A., \& SchwarTz, B. L. (1998). The mismeasure of memory: When retrieval fluency is misleading as a metamnemonic index. Journal of Experimental Psychology: General, 127, 55-68.

BRown, J. (1968). Reciprocal facilitation and impairment of free recall. Psychonomic Science, 10, 41-42.

Carroll, M., Nelson, T. O., \& Kirwan, A. (1997). Tradeoff of semantic relatedness and degree of overlearning: Differential effects on metamemory and on long-term retention. Acta Psychologica, 95, 239-253.

Castel, A. D. (2008). Metacognition and learning about primacy and recency effects in free recall: The utilization of intrinsic and extrinsic cues when making judgments of learning. Memory \& Cognition, 36, 429-437.

Castel, A. D., McCabe, D. P., \& Roediger, H. L., III (2007). Illusions of competence and overestimation of associative memory for identical items: Evidence from judgments of learning. Psychonomic Bulletin \& Review, 14, 107-111.

ChandLer, C. C. (1994). Studying related pictures can reduce accuracy, but increase confidence, in a modified recognition test. Memory \& Cognition, 22, 273-280.

Cokely, E. T., Kelley, C. M., \& Gilchrist, A. L. (2006). Sources of individual differences in working memory: Contributions of strategy to capacity. Psychonomic Bulletin \& Review, 13, 991-997.

Dodd, M. D., CAstel, A. D., \& Roberts, K. E. (2006). A strategy disruption component to retrieval-induced forgetting. Memory \& Cognition, 34, 102-111.

Dunlosky, J., \& Nelson, T. O. (1994). Does the sensitivity of judgments of learning (JOLs) to the effects of various study activities depend on when the JOLs occur? Journal of Memory \& Language, 33, 545-565.

EAKIN, D. K. (2005). Illusions of knowing: Metamemory and memory under conditions of retroactive interference. Journal of Memory \& Language, 52, 526-534. 
Glenberg, A. M., Sanocki, T., Epstein, W., \& Morris, C. (1987). Enhancing calibration of comprehension. Journal of Experimental Psychology: General, 116, 119-136.

Hertzog, C., Dunlosky, J., Robinson, A. E., \& Kidder, D. P. (2003). Encoding fluency is a cue used for judgments about learning. Journal of Experimental Psychology: Learning, Memory, \& Cognition, 29, 22-34.

KARCHMER, M. A., \& WinOGRAD, E. (1971). Effects of studying a subset of familiar items on recall of the remaining items: The John Brown effect. Psychonomic Science, 25, 224-225.

Kimball, D. R., \& Metcalfe, J. (2003). Delaying judgments of learning affects memory, not metamemory. Memory \& Cognition, 31, 918-929

Koriat, A. (1993). How do we know that we know? The accessibility model of the feeling of knowing. Psychological Review, 100, 609-639.

Koriat, A. (1995). Dissociating knowing and the feeling of knowing: Further evidence for the accessibility model. Journal of Experimental Psychology: General, 124, 311-333.

Koriat, A. (1997). Monitoring one's own knowledge during study: A cue-utilization approach to judgments of learning. Journal of Experimental Psychology: General, 126, 349-370.

Koriat, A. (2007). Metacognition and consciousness. In P. D. Zelazo, M. Moscovitch, \& E. Thompson (Eds.), The Cambridge handbook of consciousness (pp. 289-325). New York: Cambridge University Press.

KORIAT, A., \& BJORK, R. A. (2005). Illusions of competence in monitoring one's knowledge during study. Journal of Experimental Psychology: Learning, Memory, \& Cognition, 31, 187-194.

Koriat, A., \& BJoRK, R. A. (2006a). Illusions of competence during study can be remedied by manipulations that enhance learners sensitivity to retrieval conditions at test. Memory \& Cognition, 34, 959-972.

Koriat, A., \& BJork, R. A. (2006b). Mending metacognitive illusions: A comparison of mnemonic-based and theory-based procedures. Journal of Experimental Psychology: Learning, Memory, \& Cognition, 32, 1133-1145.

Koriat, A., BJork, R. A., Sheffer, L., \& Bar, S. K. (2004). Predicting one's own forgetting: The role of experience-based and theorybased processes. Journal of Experimental Psychology: General, 133, 643-656

Koriat, A., \& LEVY-SADOT, R. (2001). The combined contributions of the cue-familiarity and accessibility heuristics to feelings of knowing. Journal of Experimental Psychology: Learning, Memory, \& Cognition, 27, 34-53.

KuČERA, H., \& Francis, W. N. (1967). Computational analysis of present-day American English. Providence, RI: Brown University Press.

Leibert, T. W., \& Nelson, D. L. (1998). The roles of cue and target familiarity in making feeling of knowing judgments. American Journal of Psychology, 111, 63-75.

MAKI, R. H. (1999). The roles of competition, target accessibility, and cue familiarity in metamemory for word pairs. Journal of Experimental Psychology: Learning, Memory, \& Cognition, 25, 1011-1023.

Marsh, E. J., Dolan, P. O., Balota, D. A., \& Roediger, H. L., III (2004). Part-set cuing effects in younger and older adults. Psychology \& Aging, 19, 134-144.

Mazzoni, G., \& Nelson, T. O. (1995). Judgments of learning are affected by the kind of encoding in ways that cannot be attributed to the level of recall. Journal of Experimental Psychology: Learning, Memory, \& Cognition, 21, 1263-1274.

Metcalfe, J. (2000). Metamemory: Theory and data. In E. Tulving \& F. I. M. Craik (Eds.), The Oxford handbook of memory (pp. 197-211) Oxford: Oxford University Press.

Metcalfe, J., Schwartz, B. L., \& Joaquim, S. G. (1993). The cuefamiliarity heuristic in metacognition. Journal of Experimental Psychology: Learning, Memory, \& Cognition, 19, 851-861.

Nelson, T. O., \& Dunlosky, J. (1991). When people's judgments of learning (JOLs) are extremely accurate at predicting subsequent recall: The "delayed-JOL effect." Psychological Science, 2, 267-270.
Nelson, T. O., \& Narens, L. (1990). Metamemory: A theoretical framework and new findings. In G. H. Bower (Ed.), The psychology of learning and motivation (Vol. 26, pp. 125-173). New York: Academic Press.

NiCKerson, R. S. (1984). Retrieval inhibition from part-set cuing: A persisting enigma in memory research. Memory \& Cognition, 12, 531-552.

PeynircioĞLU, Z. F. (1987). On the generality of the part-set cuing effect: Evidence from nonmemory tasks. Journal of Experimental Psychology: Learning, Memory, \& Cognition, 13, 437-444.

REDER, L. M. (1987). Strategy selection in question answering. Cognitive Psychology, 19, 90-138.

Reysen, M. B., \& NAIRne, J. S. (2002). Part-set cuing of false memories. Psychonomic Bulletin \& Review, 9, 389-393.

Rhodes, M. G., \& CASTel, A. D. (in press). Memory predictions are influenced by perceptual information: Evidence for metacognitive illusions. Journal of Experimental Psychology: General.

Roediger, H. L., III (1978). Recall as a self-limiting process. Memory \& Cognition, 6, 54-63.

Roediger, H. L., III, \& Neely, J. H. (1982). Retrieval blocks in episodic and semantic memory. Canadian Journal of Psychology, 36, 213-242.

Roediger, H. L., III, Stellon, C. C., \& Tulving, E. (1977). Inhibition from part-list cues and rate of recall. Journal of Experimental Psychology: Human Learning \& Memory, 3, 174-188.

Rundus, D. (1973). Negative effects of using list items as recall cues. Journal of Verbal Learning \& Verbal Behavior, 12, 43-50.

SCHREIBER, T. A. (1998). Effects of target set size on feelings of knowing and cued recall: Implications for the cue effectiveness and partialretrieval hypotheses. Memory \& Cognition, 26, 553-571.

Schreiber, T. A., \& Nelson, D. L. (1998). The relation between feelings of knowing and the number of neighboring concepts linked to the test cue. Memory \& Cognition, 26, 869-883.

SlamecKa, N. J. (1968). An examination of trace storage in free recall. Journal of Experimental Psychology, 76, 504-513.

Zechmeister, E. B., \& Shaughnessy, J. J. (1980). When you know that you know and when you think that you know but you don't. Bulletin of the Psychonomic Society, 15, 41-44.

\section{NOTES}

1. Cue familiarity and accessibility accounts have been combined in some cases. For example, Koriat and Levy-Sadot (2001) suggested that familiarity operates early in judgment (cf. Reder, 1987) to determine whether a rememberer will use a cue to interrogate memory. Only after a cue is deemed sufficiently familiar will the rememberer interrogate memory and use the amount of information coming to mind as a basis for prediction. In the present study, however, we assumed that all part-set cues were sufficiently familiar that cue familiarity would not be necessary as a gating mechanism. Instead, a cue familiarity account would predict that exposure to a subset of previously studied information should inflate confidence, leading to higher predictions for the part-set cuing condition than for the free recall condition.

2. Colorado was excluded from this list because all testing took place in Colorado.

3. Studies of part-set cuing (e.g., Basden et al., 2002) frequently use the proportion of noncued items recalled as the dependent variable, so as to ensure that any differences between conditions are not due to the items used themselves. However, given that participants were asked to predict how many items they would recall out of a possible 50 (free recall condition) or 25 (part-set cuing condition), we felt that it was most appropriate to calculate measures of recall and predictions out of the total number of items possible, so as to remain faithful to predictions. However, analyses using the proportion of noncued items recalled do not change the pattern of results reported in this and subsequent experiments.

(Manuscript received April 18, 2008; revision accepted for publication July 25,2008 .) 